\title{
Сердюкова Е.Ф.
}

\section{Исследование стратегий выхода из тяжелых жизненных ситуаций с позиций системного подхода}

В данной работе представлен многомерный факторный анализ структур интегральной индивидуальности студентов с различным выходом из трудных жизненных ситуаций.

Ключевые слова: трудная жизненная ситуация, стиль поведения, структуры интегральной индивидуальности, дискриминантный анализ, коррелячионный анализ, факторный анализ, статистически значимый показатель, облические связи.

В науках о человеке все более утверждается мысль о том, что между человеком и условиями его жизни существует неразрывная связь и чтобы адекватно понять поведение человека и оказать ему социально-психологическую помощь, необходимо учитывать особенности той жизненной ситуации, в которой осуществляется его бытие и развитие. Даже вполне благополучный жизненный путь человека не обходится без трудных жизненных ситуаций, к которым можно отнести переезд из одного города в другой, смену места работы, тяжелую болезнь, уход из жизни близкого человека, развод и т.д. Таким образом, проблема трудных жизненных ситуаций в той или иной степени касается каждого человека.

Понятие «трудная жизненная ситуация» определено Н.Г. Осуховой как ситуация, «в которой в результате внешних воздействий или внутренних изменений происходит адаптация человека к жизни, в результате чего он не в состоянии удовлетворять свои основные жизненные потребности посредством моделей и способов деятельности (поведения), выработанных в предыдущие периоды жизни» [7, с. 29]. Необходимость адаптации к жизни формирует у человека определенные представления об окружающем мире и о своем месте в нем, а повседневная жизнь складывается из череды типичных ситуаций, которые привычно вписываются в хорошо освоенное внешнее пространство. Таким образом, выход за пределы хорошо освоенной повседневной реальности создает трудную жизненную ситуацию, которая может иметь как конструктивную, так и деструктивную направленность.

Крайним проявлением трудных жизненных ситуаций является экстремальная ситуация, требующая для выхода из нее максимального напряжения как моральных, так и физических сил человека.

В последнее время количество экстремальных ситуаций, повергающее большое количество людей в состояние психологического дискомфорта, значительно возросло вследствие техногенных катастроф, межнациональных конфликтов, боевых действий, участившихся террористических актов [1].

Проблематика «человек в трудных ситуациях» разрабатывается в психологии личности, социальной психологии, психотерапевтической практике и психологии труда. Изучение психологического преодоления трудных жизненных ситуаций связано с исследованиями психологической защиты (А. Фрейд, Г. Вайлант, 
Л.И. Вассерман, Ф.Е. Василюк, Р.М. Грановская, И.М. Никольская, Д. Паркер, Дж. Пери, Л.Ю. Субботина, Н. Хаан, Н. Эндлер, Э.Г. Эйдемиллер); психической и социальнопсихологической адаптации (Ф.Б. Березин, Л.Г. Дикая, Б.Д. Парыгин, А.А. Реан, Т.В. Середа, А.А. Налчаджан, С.А. Шапкин); совладания со стрессами (В.А. Бодров, А. Биллинг, С. Карвер, С. Кобаса, Б.Е. Компас, Р. Лазарус, У. Леер, Р. Моос, К. Олдвин, Л. Перлин, Г. Томэ, Ш. Фолкман, М. Шейер); саморегуляции деятельности и поведения, регуляции функциональных состояний (В.А. Бодров, Л.Г. Дикая, О.А. Конопкин, А.Б. Леонова, В.Л. Марищук, В.И. Моросанова, А.К. Осницкий, А.О. Прохоров, Е.А. Сергиенко); активности и ее роли в преодолении жизненных трудностей (Б.Г. Ананьев, К.А. Абульханова, А.К. Белоусова, А.В. Брушлинский, А.Н. Дёмин, В.В. Знаков, Т.Л. Крюкова, Б.Ф. Ломов, В.А. Петровский, С.Л. Рубинштейн) [4].

В пятигорской психологической школе под руководством В.В. Белоуса $[3,8]$ проведен ряд психологических исследований, направленных на изучение структур интегральной индивидуальности студентов (Ф.М. Шидакова, 1991; А.Т. Найманов, 1991; Л.В. Мищенко, 1993; Е.Я. Михитарьянц, 1993; Нгуен Кхак Тхан, 2002; А.А. Урусов, 2001; Р.Г. Боязитов, 2004; И.Ю. Ширяева, 2005; С.В. Гринь, 2008; И.Н. Зиник, 2009 и т.д.) [2, 6]. Однако данные о структурах интегральной индивидуальности студентов с различным выходом из тяжелых жизненных ситуаций отсутствуют [3].

Изучение уже имеющихся результатов научных изысканий позволило нам инициировать экспериментальное исследование, которое проводилось в 20072008 году в Чеченском государственном университете. Испытуемыми являлись студенты второго и третьего курса филологического факультета (18-19 лет), при этом все они принимали участие в психологическом эксперименте впервые. Исследование проходило в эмоционально-положительной атмосфере, с добровольного согласия всех участников эксперимента.

Предметом изучения мы определили изменения, происходящие в структурах интегральной индивидуальности после преобразующего эксперимента в сравнении с констатирующим.

Экспериментальное исследование проходило в несколько этапов.

На первом этапе осуществлялась диагностика студентов (всего 88 человек) по ведущей методике (Немов) и формировались группы (борцы и соглашатели), затем проводилась диагностика свойств нейродинамического, психодинамического, личностного и метаиндивидуального уровней интегральной индивидуальности участников исследования.

Второй этап был направлен на подготовку к формирующему эксперименту, в качестве которого нами был выбран тренинг достижения цели (трансформирование адаптивного стиля человеческого поведения в преобразующий).

С учетом сложности и многоплановости такого феномена как стиль поведения, коррекционно-развивающая работа представляла собой несколько циклов, каждый из которых имел свои, относительно самостоятельные, цели и направленность: 
- мощная и энергетически насыщенная работа по повышению самооценки;

-отработка умения четко и позитивно формулировать цель, составлять алгоритм действий;

-тренинг уверенного поведения.

В соответствии с целями коррекционно-развивающей работы третий этап исследования - формирующий эксперимент в группе соглашателей - представлял собой три блока тренинговых занятий: тренинг повышения самооценки; тренинг, направленный на умение четко и позитивно формулировать цель, составлять алгоритм действий; тренинг уверенного поведения.

На четвертом этапе проводилась повторная диагностика структур интегральной индивидуальности участников эксперимента.

Исследование показало, что система специально подобранных тренингов является объективной детерминантой и системообразующим фактором, определяющим специфику развития структур интегральной индивидуальности студентов с различным выходом из тяжелых жизненных ситуаций. Структуры интегральной индивидуальности студентов группы «борцов» упорядочены, организованы и уплотнены, характеризуется значительной приспособительной ролью высших (личностный и социально-психологический) уровней; структуры интегральной индивидуальности студентов группы «соглашателей» менее гармоничны, ортогональны и обладают выраженным перевесом низших уровней над высшими.

Мы выдвинули гипотезу о том, что основным психологическим условием развития структур интегральной индивидуальности студентов группы «соглашателей» является целенаправленное, психологическое сопровождение, в основе которого лежит единство концептуальных положений, системы критериев и средств диагностики, используемых психотехнологий и способов, направленных на изменение мировоззренческих и психологических установок студента, на содействие процессам личностного развития, уверенного поведения и повышения самооценки студентов. Психологическое сопровождение развития интегральной индивидуальности студентов группы «соглашателей» результативно в том случае, если включает в себя создание условий для принятия студентом оптимальных решений в тяжелых жизненных ситуациях; предполагает позитивное целеполагание и последовательность действий, ориентируется на внутренний потенциал студента, на его право самостоятельно совершать выбор и в дальнейшем нести ответственность.

Процесс реализации программы психологического сопровождения приводит к качественному преобразованию структур интегральной индивидуальности группы «соглашателей», расширяет круг разноуровневых связей, приводит к изменению не только отдельных свойств интегральной индивидуальности студентов группы «соглашателей», но и всей структуры в целом, которая становится гармоничнее, пластичнее и обогащается много-многозначными связями.

Интегральные психологические портреты студентов с различным способом выхода из тяжелых жизненных ситуаций существенно различаются. Статистическое 
сопоставление структур интегральной индивидуальности групп «борцов» и «соглашателей» до реализации тренинговой программы выявило 53 \% достоверных значимых различий. Дискриминантный анализ обнаружил достоверные различия по комплексным показателям четырех уровней в отдельности, по интегральным показателям низших и высших уровней и по общему интегральному показателю всех уровней.

Межуровневый корреляционный анализ структур интегральной индивидуальности «борцов» и «соглашателей» не совпадает. Структуры интегральной индивидуальности группы «борцов» являются более упорядоченными, чем в группе «соглашателей». В группе «соглашателей» значительную роль в формировании структур интегральной индивидуальности играют нейродинамический и психодинамический (природные) уровни, тогда как в группе «борцов» главенствующая роль принадлежит психодинамическому, личностному и социально-психологическому уровням. Межуровневая структура интегральной индивидуальности группы «борцов» более уплотнена и упорядочена, чем межуровневая структура интегральной индивидуальности группы «соглашателей».

Факторный анализ установил, что структура интегральной индивидуальности студентов группы «борцов» более гармонична (выделено три полных фактора), чем структура индивидуальности студентов группы «соглашателей» (выделено два полных и два частичных фактора). По средней степени насыщенности факторными весами в структуре интегральной индивидуальности студентов группы «соглашателей» доминируют природные уровни, в группе «борцов»- высшие уровни. В структуре интегральной индивидуальности студентов группы «соглашателей» межфакторные структуры представлены малым количеством облических связей (4) и большим количеством ортогональных связей (15), а в группе «борцов» количество облических связей более чем в 2 раза превосходит этот показатель группы «соглашателей» (9), в то время как количество ортогональных связей меньше, чем в группе соглашателей (12).

В результате формирующего эксперимента структура интегральной индивидуальности экспериментальной группы статистически значимо изменилась; в то время как в контрольной группе статистически значимых изменений не произошло.

Поэлементный анализ показал, что эффективность влияния тренинга на развитие структур интегральной индивидуальности студентов группы «соглашателей» экспериментальной группы по отдельным свойствам составил 30,4 \%; в контрольной группе таких изменений выявлено не было.

Таким образом, многомерный факторный анализ позволил констатировать, что структуры интегральной индивидуальности студентов, прошедших тренинг развития структур интегральной индивидуальности студентов группы «соглашателей», стали более гибкими и упорядоченными, приобрели более высокий приспособительный потенциал и по своему развитию приблизились к группе «борцов». В контрольной группе обнаруженные изменения в факторной структуре незначительны. 


\section{Литература}

1. Белоус В.В., Боязитова И.В. Системное познание индивидуальности человека. Пятигорск: ПГЛУ, 2009.

2. Белоус В.В., Михитарьянц Е.Я. Влияние разноуровневых основ интегральной индивидуальности на результативность совместной мыслительной деятельности // Формирование профессиональной личности учителя. - Пятигорск, 1992. - 12 c.

3. Боязитова И.В., Нгуен Кхак Тхан, Белоус В.В. Особенности структур интегральной индивидуальности у студентов с различной адаптированностью к требованиям высшей школы / Тезисы докл. Третьего Международного Конгресса. Симпозиум 8: Интегральная антропология. Когнитивная психология. Этнопсихология. Пятигорск, 2001. - С. 29-32.

4. Интегральная индивидуальность человека и ее развитие / Под ред. Б.А. Вяткина. М., 1999. - 327 с.

5. Мерлин В.С. Очерк интегрального исследования индивидуальности. - М., Педагогика. 1986.

6. Найманов А.Т. Экспериментальное исследование проблемы распознавания разноуровневых основ индивидуальности студентов педвуза: автореф. дис.... канд. психол. наук. - Ростов-на-Дону, 1991. - 20 с.

7. Ромек В.Г. Психологическая помощь в кризисных ситуациях. - СПб.: Речь, 2004. -256 c.

8. Ширяева И.Ю., Развитие структур интегральной индивидуальности студентов с полярным отношением к ценностям: расточительные и бережливые студенты: автореф. дис. ... док-ра психол. наук. - Ставрополь, 2005. - 31 с. 